\title{
Modification of perchery system: Preference for ramps rather than ladders during early adaptation period for cage-reared pullets
}

\author{
Hongya Zheng ${ }^{1,4}$, Baoming $\mathrm{Li}^{1,2,3}$, Qin Tong ${ }^{1,2,3^{*}}$, Gang Chen ${ }^{1,2,3}$, Xuanyang $\mathrm{Li}^{1,2,3}$ \\ (1. College of Water Resources and Civil Engineering, China Agricultural University, Beijing 100083, China; \\ 2. Key Laboratory of Agricultural Engineering in Structure and Environment, Ministry of Agriculture and Rural Affairs, Beijing 100083, \\ China; 3. Beijing Engineering Research Center for Livestock and Poultry Healthy Environment, Beijing 100083, China; \\ 4. College of Engineering, Huazhong Agricultural University, Wuhan 430070, China)
}

\begin{abstract}
Poor early adaptation in aviaries has adverse effects on welfare and the later production. Effects of system modification by ramps and ladders on early adaptation of birds were investigated. A total of 240 pullets and 24 cockerels of Yukou Jing Pink II parent stock were allocated into six perchery compartments at the age of 83 days from conventional cages. Three compartments were modified with ramps of different angles, $30^{\circ}, 40^{\circ}$ and $30^{\circ} \& 50^{\circ}$ combination. The other compartments were fitted with 2 ladders, with $22 \mathrm{~cm}$ steps and $33 \mathrm{~cm}$ steps. Spatial distribution of birds and eggs, as well as the data of ramps and ladders utilization were used to assess birds' adaptation and the effectiveness of modification facilities. A higher proportion of hens got onto the tiered platforms in ramp group $(p<0.001)$ and engaged in feeding $(p=0.002)$. Inversely more than $85.0 \%$ of hens dwelled on the system floor in the ladder group for the whole observation period. The proportion of birds feeding increased over time $(p<0.001)$, with the proportion of birds lying decreasing $(p<0.001)$. A higher frequency of utilization of ramps was found compared with ladders (4.5-25.8 vs. 2.8-14.7 times/40 birds per hour). For ramp use, $79.3 \%$ of hens negotiated level change by using $30^{\circ} \mathrm{ramp}$ and behavioral process was also found related with the type of ramps. On the contrary, very few successful level changes were observed via ladders and $60 \%$ of ladder use was ended with birds backing to the system floor. Besides, a higher proportion of non-nest eggs was recorded in ladder group in the early laying period. These results indicated that modification of ramps is more applicable for improving birds' early adaptation and later production in perchery system of multi-tier, especially for pullets reared in conventional cages.
\end{abstract}

Keywords: animal welfare, modification, perchery system, adaptation, pullet, ramp, enriched cage system DOI: $10.25165 /$ j.ijabe.20191204.4030

Citation: Zheng H Y, Li B M, Tong Q, Chen G, Li X Y. Modification of perchery system: Preference for ramps rather than ladders during early adaptation period for cage-reared pullets. Int J Agric \& Biol Eng, 2019; 12(4): 34-42.

\section{Introduction}

Movements and behavioral repertoire of birds are restricted in conventional cages because of the limited space and barren environment ${ }^{[1-4]}$, which is thought unfriendly for animal welfare. Therefore, conventional cage systems for laying hens are required to be phased out by 2012 in $\mathrm{EU}^{[5,6]}$ and replaced by enriched cage systems with more space and environmental enrichments according to the Egg Products Inspection Act Amendments of 2012 (HR $3798)^{[7]}$. In recent years, animal welfare concerns are becoming increasingly publicized in China, especially among scientists, associations and producers, as well as government officials, which in turn have a great impact on reformation of housing systems.

Researches and collaborations promote the reformation and

\section{Received date: 2017-12-10 Accepted date: 2018-05-29}

Biographies: Hongya Zheng, Lecturer, research interest: animal housing and welfare, Email: zhyhzau@mail.hzau.edu.cn; Baoming Li, Professor, research interest: housing system, environment and animal welfare for livestock and poultry, Email: libm@cau.edu.cn; Gang Chen, Associate Professor, research interest: housing system and equipment for livestock and poultry, Email: chengang@cau.edu.cn; Xuanyang Li, PhD candidate, research interest: waste management and technology, Email: 541533870@qq.com.

*Corresponding author: Qin Tong, Lecturer, research interest: precision livestock farming and animal welfare. College of Water Resources and Civil Engineering, China Agricultural University, No. 17 Qinghua East Road, Haidian District, Beijing 100083, China. Tel: 86-10-62736181, Fax: 86-10-62736904, Email: tongqin@cau.edu.cn. upgrading of housing systems and also demand a corresponding transition period meanwhile. For laying hens, cage-free systems, mostly well-known like aviaries, which featured multi-tier levels of three-dimensional space ${ }^{[8]}$ and have either integrated nest boxes or separate ones, are increasingly being used in production as alternative systems for conventional cages ${ }^{[9]}$. Such systems provide birds more space and opportunities to perform more natural behaviors $^{[4,10]}$ so as to improve the bone strength of birds ${ }^{[3,11,12]}$. However, several problems remain in practice regarding the use of three-dimensional space, with which health condition of birds and production performance are related.

Numerous researches have indicated that the use of space or facilities in three-dimensional system ${ }^{[13-15]}$, and both behaviors and health of birds in laying production depend largely on their rearing conditions $^{[16,17]}$. For management convenience of vaccinations, which are up to a dozen times, the majority of day-old chicken in China would be housed in cages before laying eggs, even until the end of production. However, barren environment in the early rearing period has adverse effects on birds' ability of spatial navigation ${ }^{[18]}$, also known as spatial ability, the ability to orient in the environment ${ }^{[19]}$, which is crucial for birds in aviaries because of decentralized resources on different levels in the system. It was found that fewer cage-reared birds spent time on perches and on the elevated platform compared to the aviary-reared birds at the age of 19 weeks $^{[15]}$. Poor spatial ability or resource use might be related with a higher proportion of floor eggs in cage-free systems $^{[20]}$. How to increase space use in the multi-tier systems 
is important for later production, particularly for cage-reared pullets, which were found having poorer ability to perform spatial tasks compared to those raised in aviaries ${ }^{[18]}$.

Measures like offering transition facilities are took to decrease occurrences of deformity or fractures of keel bones ${ }^{[21-23]}$ by enabling birds to perform more balanced movements and reduce the occurrences of falls and collisions. Related researches demonstrated that structural parameters including the forms of modification facilities and angles of ramps would impact the use of facilities and related behaviors ${ }^{[24,25]}$. The objectives of this study were to investigate the patterns of early adaptation of cage-reared birds in a multi-tiered perchery system over time after transfer and find applicable facilities for transition adaptation. This study expected to find modification facilities with optimal design which was determined by its usage frequency and behavioral expression of birds during use. Basically, space usage determined by the distribution of hens over time and the ratio of floor eggs in the initial laying period were used to judge the practical effect. This research expect that information above would embolden our understanding of how spatial modifications influence birds' adaptation in the three-dimensional system.

\section{Materials and methods}

\subsection{Ethics statement}

All birds were supervised by trained staff with standard guidelines for layer breeders of Beijing Huadu Yukou Poultry Co. Ltd. Animal research in this study obtained approval from the Animal Welfare Committee of China Agricultural University.

\subsection{Birds and housing}

Non-beak trimmed pullets $(N=240)$ and cockerels $(N=24)$ of Yukou Jing Pink II parent stock (Rhode Island White Hybrids) were raised in conventional cages (8 pullets/cage and 3 cockerels/cage from 8 weeks of age, with a space allowance of $487.5 \mathrm{~cm}^{2} /$ pullet and $720 \mathrm{~cm}^{2} /$ cockerel, and $8.1 \mathrm{~cm}$ of feeder space/pullet and $18 \mathrm{~cm}$ of feeder space/cockerel) on a commercial farm of Beijing Huadu Yukou Poultry Co. Ltd. in Beijing, China. Detailed information of rearing condition can be found in reference [26]. At the age of $83 \mathrm{~d}$, all birds were evenly mixed and distributed into 6 perchery compartments in an experimental layer house located in Shangzhuang experiment station of China Agricultural University. Every 40 pullets and 4 cockerels were put into one compartment. All birds were placed on the system floor at the beginning to monitor the adaptation process for the upper space in the system. Perchery compartments were separated by metal wire mesh with a reserved door that could be used for internal inspection. Each compartment consisted of 3 -tiered platforms and one nest tier above the system floor, and measured $200 \mathrm{~cm}(\mathrm{~W}) \times 150 \mathrm{~cm}(\mathrm{D}) \times 280 \mathrm{~cm}(\mathrm{H})$, providing each bird with $1307 \mathrm{~cm}^{2}$ of usable area (including $681.8 \mathrm{~cm}^{2}$ of plastic floor area and $625.2 \mathrm{~cm}^{2}$ of cage wire space), $37.5 \mathrm{~cm}$ of perch space, $18 \mathrm{~cm}$ of feeding space and $150 \mathrm{~cm}^{2}$ of nest area, and 3.7 birds per nipple water. Detailed information was shown in Figure 1a. Feed and water were provided ad libitum and the lighting schedule was 9.5 L: $14.5 \mathrm{D}$ (07:00 to 16:30) with 30-min twilight phase at the end of the light period. Light was on throughout the first night after transfer in order to facilitate birds' feeding and drinking. Belt underneath was used for manure convey once per day.

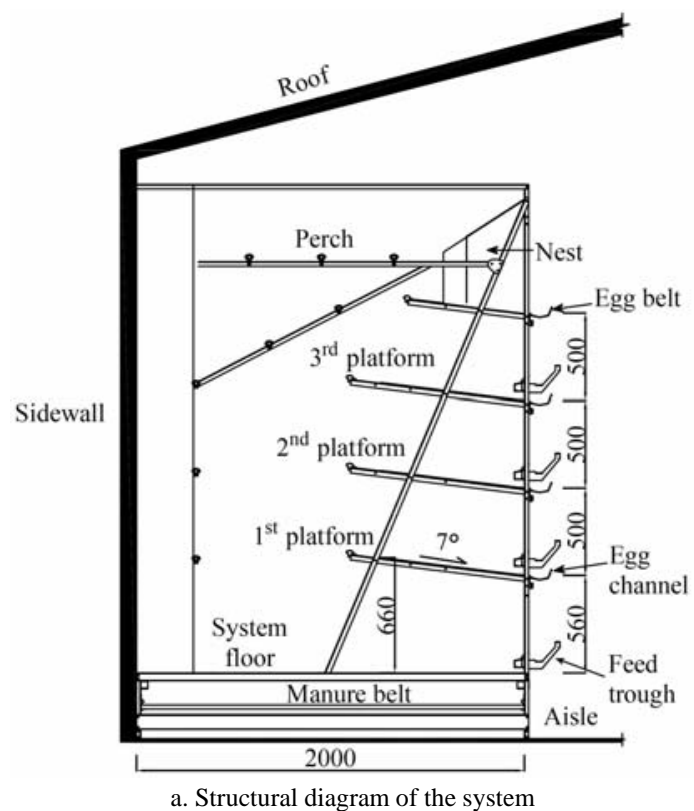

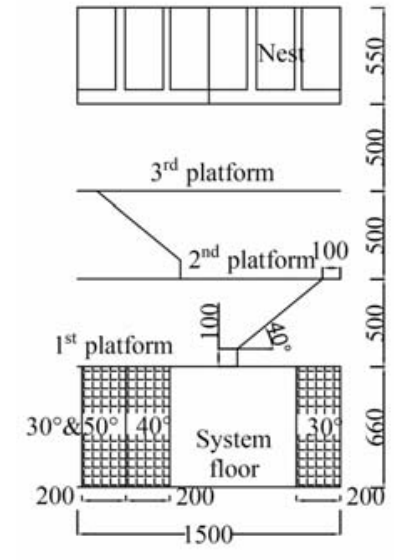

b. Schematic view of ramp modification
Unit: mm
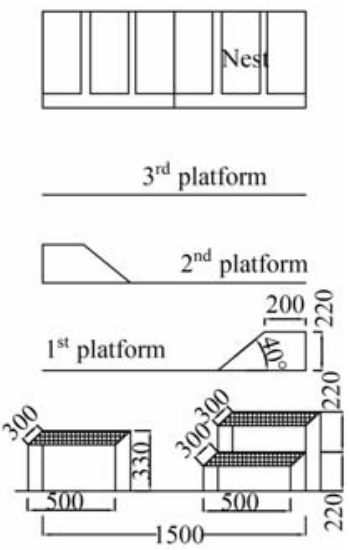

c. Schematic view of ladder modification in one compartment

Note: Two group nests were separated by perforated metal panel above the $3^{\text {rd }}$ platform and perches were available at different height.

Figure 1 Schematic view of a perchery compartment, feed and water were available both on the system floor and on all platforms

\subsection{Modification of perchery compartments}

Totally 6 perchery compartments were modified, in which 3 compartments were provided with ladders and the others with ramps. Each ladder compartment had 2 ladders, either consisted of two $22 \mathrm{~cm}$ steps in height (L22) or only had one $33 \mathrm{~cm}$ step in height (L33) from the system floor to the $1^{\text {st }}$ platform. For ramp compartments, 3 ramps of different angles, angles of $30^{\circ}$ (R30), $40^{\circ}$ (R40) and a combination of $30^{\circ}$ and $50^{\circ}$ (R30\&50), were simultaneously installed connecting the system floor and the $1^{\text {st }}$ platform. Surface of ramps and ladders were made of metal wire mesh and supported by angle iron framework for stability. Besides, ramps or ladders were also installed between other platforms accordingly. Detailed modification information of ramps and ladders was presented in Figures $1 \mathrm{~b}$ and 1c.

\subsection{Distribution and behavioral observation}

Because of the overcrowding and serious overlap of photographed hens, birds' distribution (only for hens) in defined areas was recorded by direct observation. Distribution was 
recorded 5 times in the morning and 5 times in the afternoon per compartment during light hours, and only once at night just $1 \mathrm{~h}$ after light off, when birds would not ever change their locations between tiers. The defined areas in present perchery system were: (i) system floor; (ii) the $1^{\text {st }}$ platform; (iii) the $2^{\text {nd }}$ platform; (iv) the $3^{\text {rd }}$ platform; (v) perches of all height; (vi) modification facilities (ramps or ladders). No birds were found to use nest area during observation so the nest area was not included as a defined area. All compartments were scanned in random order during the daytime but orderly at night because there was no change of birds' distribution when night observation was on. To minimize the disturbance towards hens at night, observation was done with the use of a masked flashlight.

After distribution observation, behavioral recording for group was conducted once in the morning and once in the afternoon. Number of hens performing feeding, standing, lying, moving, aggression, comfort behaviors (including preening, stretching, wing flapping and head scratching), exploring and roosting was counted, dividing which by the total number of hens of one compartment, could get a target behavioral percentage. Infrared cameras (Dahua DH-IPC-HFW4300R-Z, Zhejiang, China), which were fixed on the sidewall, were used to tally the occurrence of ramp use and ladder use from 09:00 to 10:00 and from 15:00 to 16:00. According to behavioral difference (Table 1 for detailed description), processes when using ramps or ladders were classified into 5 categories based on the completeness and time spent for level change between the system floor and the $1^{\text {st }}$ platform. Usage frequencies of modification facilities were the summed occurrences of all 5 behavioral processes. Both direct observation and video observation above were ended on the $14^{\text {th }}$ day after housing.

Table 1 Description of behavioral processes during level change for the ramp use and the ladder use

\begin{tabular}{|c|c|c|}
\hline Type of process & Description & Time spent \\
\hline DM & $\begin{array}{l}\text { A success level change by moving up or down } \\
\text { between the system floor and the } 1^{\text {st }} \text { platform } \\
\text { directly without stay or linger halfway. }\end{array}$ & $<120$ s \\
\hline Linger & $\begin{array}{l}\text { A success level change by moving up or down } \\
\text { between the system floor and the } 1^{\text {st }} \text { platform with } \\
\text { lingering halfway. }\end{array}$ & $<120 \mathrm{~s}$ \\
\hline Back & $\begin{array}{l}\text { Uncompleted level change with a bird going back to } \\
\text { the starting point halfway without/before arrival at } \\
\text { the predicted destination. }\end{array}$ & $<120$ s \\
\hline Stay & $\begin{array}{l}\text { Uncompleted level change with hesitation or stay } \\
\text { halfway instead. }\end{array}$ & $\geqslant 120 \mathrm{~s}$ \\
\hline Fall & Failed level change with a fall onto the system floor. & $<120 \mathrm{~s}$ \\
\hline
\end{tabular}

\subsection{Data collection for eggs}

Eggs that were laid in the nests, on platforms and on the system floor were separately counted every day in each compartment from the beginning of laying eggs until 25 weeks of age. Only eggs laid on the system floor were regarded as floor eggs while eggs on platforms were regarded as system eggs.

\subsection{Statistical analyses}

All analyses were conducted in IBM SPSS Statistics 20.0 (SPSS, I. (2011), IBM SPSS statistics for Windows, version 20.0. New York: IBM Corp.) and effects were perceived as significant when $p<0.05$. Standardized residuals of each outcome variable were firstly checked for normality using Q-Q plots, with proper transformations performed on variables where possible. Tukey HSD was used for multiple comparisons.

Distribution of hens on 6 defined areas was presented as percentages in relation to the total number of hens per day per compartment. For daytime distribution, the model included modification, days of adaptation, compartment and their interaction as fixed effects. For night-time distribution and group behaviors, the model included modification, days of adaptation and their interaction as fixed effects. The statistical models were of the following forms:

For daytime distribution of hens:

$Y_{i j k}=u+M_{i}+D_{j}+C_{k}+(M D)_{i j}+(M C)_{i k}+(D C)_{j k}+(M D C)_{i j k}+\varepsilon_{i j k}$

For night-time distribution and group behaviors:

$$
Y_{i j}=u+M_{i}+D_{j}+(M D)_{i j}+\varepsilon_{i j}
$$

where, $Y_{i j k}$ is the response variable on day $j$ in compartment $k$ with modification $i$; $Y_{i j}$ is response variable on day $j$ with modification $I$; $u$ the intercept; $M_{i}$ the modification (ramp or ladder) effect; $D_{j}$ the effect of days of adaptation; $C_{k}$ the compartment (1, 2 and 3) effect; $(M D)_{i j},(M C)_{i k},(D C)_{j k}$ and $(M T C)_{i j k}$ are interaction effects; $\varepsilon_{i j k}$ and $\varepsilon_{i j}$ are error effects.

The utilization of modification facilities was compared using Student's $t$-test and relationship between behavioral processes and structural characteristics of modification facilities was determined using the Chi-square test. For compartments with the same modification, Friedman test was used for frequency analysis between facilities of different parameters to find out the preferential type of facility of birds. For certain type of ramps or ladders, difference between behavioral processes was analyzed as percentage in relation to the total number of modification facility use during observation and Kruskal-Wallis test was used.

For effects on egg information, one-way ANOVA or Mann-Whitney $U$ test was used. Egg distribution in different areas was presented as percentage in relation to the total number of eggs per week per compartment.

\section{Results}

\subsection{Distribution of hens during adaptation period}

Percentages of hens on the $1^{\text {st }}$ tier, the $3^{\text {rd }}$ tier, on modification facilities and on perches were significantly affected by interaction of modification $x$ days of adaptation and modification $\times$ compartment, indicating distinct adaptation condition over time with different modification and also difference in separate compartments (Table 2). For proportion of hens on system floor and on the $2^{\text {nd }}$ tier, modification $\times$ compartment interaction had a significant impact (Table 2). Besides, proportion of hens on system floor also decreased greatly over time, resulting from the noteworthy effect of days of adaptation. Although significant effect of compartments on distribution was found, which exceeded expectation and might be reduced by increasing replications if possible, only effects of modification, day of adaptation and their interaction was considered in the following analysis because of the similar change rule of hen distribution on defined areas in all 3 compartments of the same modification.

During observation, proportion of hens on the $1^{\text {st }}$ platform in ramp compartments showed a significant decrease over time $(p<0.001)$, decreased from the upmost $30.8 \% \pm 3.0 \%$ on the $3^{\text {rd }}$ day to lowest $8.3 \% \pm 3.4 \%$ on the $13^{\text {th }}$ day, as shown in Figure 2. On the contrary, proportion of hens on the $3^{\text {rd }}$ platform in ramp compartments gradually increased from $11.7 \% \pm 3.5 \%$ on the $2^{\text {nd }}$ day to $44.6 \% \pm 6.2 \%$ on the $12^{\text {th }}$ day $(p<0.001$, Figure 2$)$. Although not so many hens got onto perches, a significant proportion increase of hen on perches in ramp compartments in later $4 \mathrm{~d}$ was found. Proportion of hens on tiered platforms in ramp compartments finally reached $76.7 \%$ in the daytime. For hens in ladder compartments, $85.0 \%$ of hens located themselves on 
the floor in the daytime with an inconspicuous decrease from the beginning to the end of observation. Unlike hens in ramp compartments reaching all tiered platforms, ladder hens were observed reaching as far as the $1^{\text {st }}$ platform only.

Table 2 Results of analyses for fixed effects of modification, compartment, days of adaptation on proportion of hens in the daytime in six defined areas

\begin{tabular}{|c|c|c|c|c|c|c|c|c|c|c|c|c|c|}
\hline \multirow{2}{*}{ Factor } & \multirow{2}{*}{$d . f}$. & \multicolumn{2}{|c|}{ System floor } & \multicolumn{2}{|c|}{$1^{\text {st }}$ tier } & \multicolumn{2}{|c|}{$2^{\text {nd }}$ tier } & \multicolumn{2}{|c|}{$3^{\text {rd }}$ tier } & \multicolumn{2}{|c|}{ Ramp or ladder } & \multicolumn{2}{|c|}{ Perches } \\
\hline & & $F$ & Sig. & $F$ & Sig. & $F$ & Sig. & $F$ & Sig. & $F$ & Sig. & $F$ & Sig. \\
\hline$M$ & 1 & 2359.639 & $<0.001$ & 95.524 & $<0.001$ & 556.807 & $<0.001$ & 475.268 & $<0.001$ & 0.746 & 0.388 & 7.758 & 0.006 \\
\hline$D$ & 11 & 3.056 & 0.001 & 2.380 & 0.008 & 0.399 & 0.956 & 6.460 & $<0.001$ & 0.877 & 0.564 & 2.336 & 0.009 \\
\hline$C$ & 2 & 96.377 & $<0.001$ & 9.423 & $<0.001$ & 30.965 & $<0.001$ & 8.657 & $<0.001$ & 0.746 & 0.475 & 0.939 & 0.392 \\
\hline$M D$ & 11 & 1.319 & 0.213 & 4.960 & $<0.001$ & 0.392 & 0.959 & 6.816 & $<0.001$ & 2.309 & 0.010 & 2.468 & 0.006 \\
\hline$M C$ & 2 & 17.267 & $<0.001$ & 29.554 & $<0.001$ & 30.242 & $<0.001$ & 7.876 & $<0.001$ & 8.985 & 0.000 & 5.303 & 0.005 \\
\hline$D C$ & 22 & 0.760 & 0.774 & 0.800 & 0.726 & 1.423 & 0.102 & 0.371 & 0.996 & 1.104 & 0.341 & 1.105 & 0.340 \\
\hline$M D C$ & 22 & 1.579 & 0.050 & 1.418 & 0.104 & 1.440 & 0.095 & 0.411 & 0.992 & 0.681 & 0.857 & 0.906 & 0.587 \\
\hline
\end{tabular}

Note: $M=$ modification (ramp or ladder), $D=$ days of adaptation, $C=$ compartment. $M D, M C, D C$ and $M D C$ were interaction effect of two or three fixed factors above.
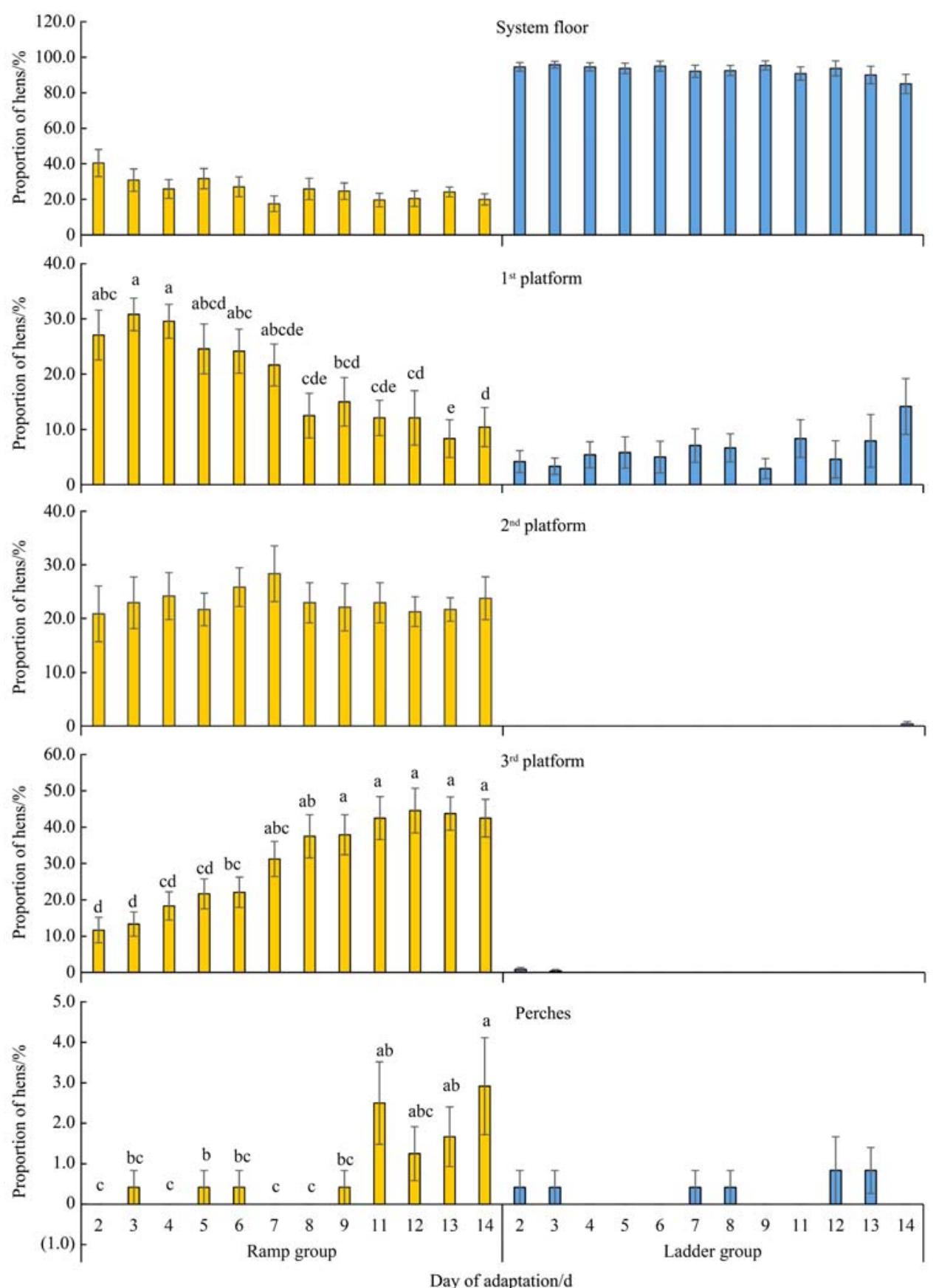

Note: Letters a-e indicate difference within days of adaptation. Data on the $10^{\text {th }}$ day was missing because of an emergent interview with a doctor.

Figure 2 Change of birds' distribution in the daytime in defined areas over time in both ramp compartments and ladder compartments 
Similar with the condition in the daytime, percentage of hens at night on the $1^{\text {st }}$ platform and the $3^{\text {rd }}$ platform was significantly affected by modification $\times$ days of adaptation interaction (Table 3 ). For hens on system floor, on the $2^{\text {nd }}$ platform and on modification facilities, only effect of modification was found (Table 3).

Proportion of hens on the $1^{\text {st }}$ tier in ramp compartments showed a slow decline over time at night but with a non-significant increase in ladder compartments (Figure 3). Similar with the condition in the daytime, there were increasingly more hens reaching the $3^{\text {rd }}$ platform with longer adaptation (Figure 3). More hens remained on the system floor in ladder compartments than those in ramp compartments $(p<0.001)$, along with significantly fewer hens on the $2^{\text {nd }}$ platform $(p<0.001)$ and more hens using the modification facilities $(p<0.001)$ (Figure 4).

Table 3 Results of analyses for fixed effects of modification and days of adaptation on proportion of birds at night in six defined areas

\begin{tabular}{|c|c|c|c|c|c|c|c|c|c|c|c|c|c|}
\hline \multirow{2}{*}{ Factor } & \multirow{2}{*}{ d.f. } & \multicolumn{2}{|c|}{ System floor } & \multicolumn{2}{|c|}{$1^{\text {st }}$ tier } & \multicolumn{2}{|c|}{$2^{\text {nd }}$ tier } & \multicolumn{2}{|c|}{$3^{\text {rd }}$ tier } & \multicolumn{2}{|c|}{ Ramp or ladder } & \multicolumn{2}{|c|}{ Perches } \\
\hline & & $F$ & Sig. & $F$ & Sig. & $F$ & Sig. & $F$ & Sig. & $F$ & Sig. & $F$ & Sig. \\
\hline$M$ & 1 & 1062.942 & $<0.001$ & 129.673 & $<0.001$ & 186.067 & $<0.001$ & 423.985 & $<0.001$ & 22.654 & $<0.001$ & 1.780 & 0.188 \\
\hline$D$ & 11 & 1.411 & 0.199 & 0.496 & 0.897 & 0.596 & 0.823 & 4.998 & $<0.001$ & 0.876 & 0.569 & 1.413 & 0.198 \\
\hline$M D$ & 11 & 0.493 & 0.899 & 2.303 & 0.023 & 0.519 & 0.881 & 5.213 & $<0.001$ & 0.405 & 0.947 & 0.617 & 0.805 \\
\hline
\end{tabular}

Note: $M=$ modification (ramp or ladder), $D=$ days of adaptation, and $M D=$ interaction effect of the two fixed factors.
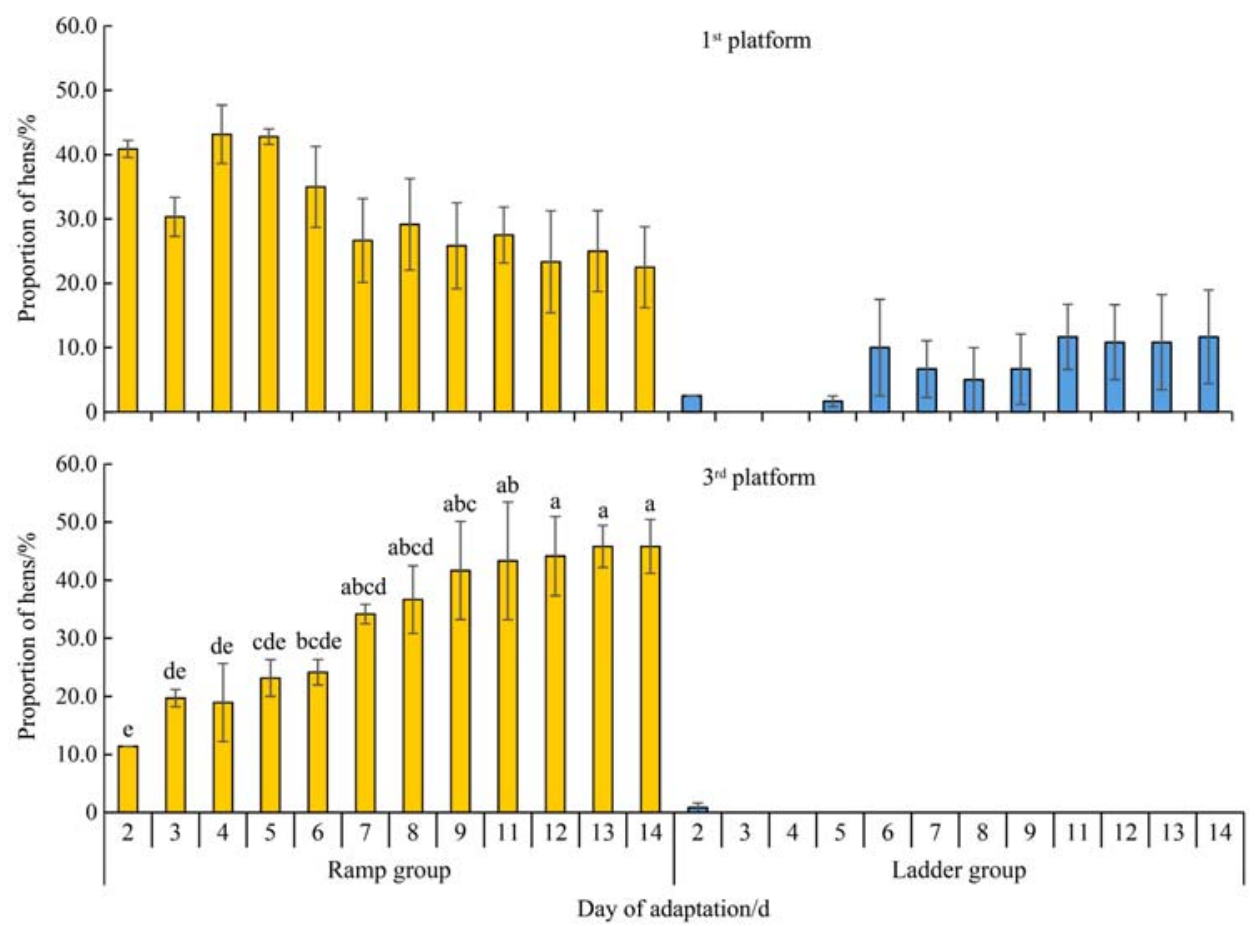

Note: Letters a-e indicate difference $(p<0.05)$ within days of adaptation. Data on the $10^{\text {th }}$ day during observation was missing because of an emergent interview with a doctor.

Figure 3 Change of birds' distribution at night on the $1^{\text {st }}$ platform and the $3^{\text {rd }}$ platform over time in both ramp compartments and ladder compartments

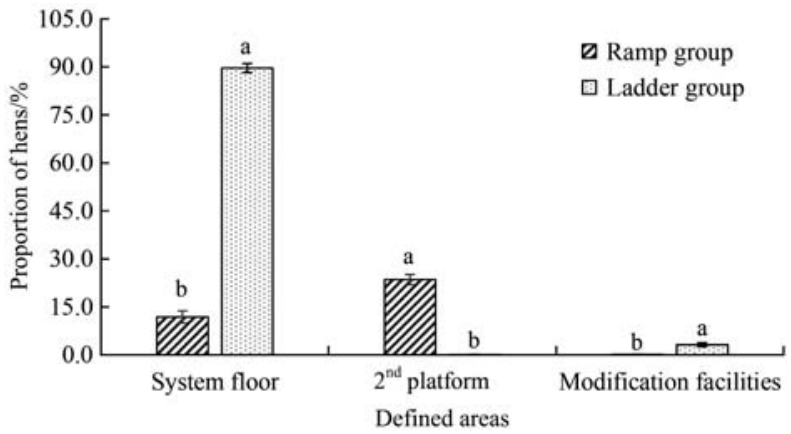

Note: Letters a-b indicate difference $(p<0.05)$ between modification treatments.

Figure 4 Proportion of hens on system floor, the $2^{\text {nd }}$ platform and modification facilities in ramp group an ladder group

\subsection{Utilization of ramp and ladder and behavioral difference}

Generally, average ramp utilization was more frequent than ladder in the 1-h period per day (ramps: 4.5-25.8 times/40 birds; ladders: 2.8-14.7 times/40 birds). Remarkable difference was found on the $11^{\text {th }}$ day $(p=0.045)$, the $13^{\text {th }}$ day $(p=0.011)$ and the $14^{\text {th }}$ day ( $p=0.046$ ) between modifications (Figure 5).

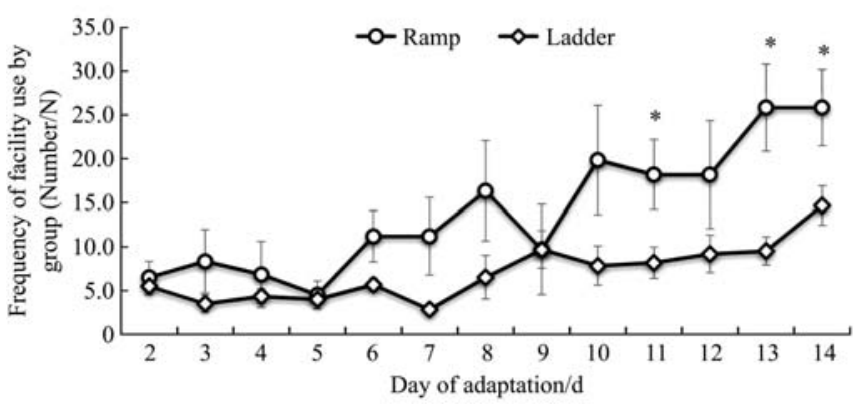

Note: * indicates difference between ramp group and ladder group at the level of $p<0.05$.

Figure 5 Frequency of facility use per hour from the $2^{\text {nd }}$ day until the $14^{\text {th }}$ day after transfer 
Hens showed preference for certain ramp and ladder as indicated by the more frequent usage frequency and various behavioral processes. In ramp group, $79.3 \%$ of hens negotiated level change by using R30, significantly more than that using R40 $(p=0.003)$ and R30\&50 $(p<0.001)$. Moreover, behavioral process was also found related with the type of ramps $(p<0.001)$. Hens inclined to perform DM when using ramps and there was remarkable percentage difference of behavioral processes for ramps $(p<0.001$, Table 4). For R30\&50 use, DM accounted for $60.2 \%$, and this proportion increased to $68.4 \%$ for R30 use, and $94.3 \%$ for R40 use. Besides, the highest Back ratio was found when using R30\&50, accounting for $38.8 \%$. In ladder groups, $90.1 \%$ of hens chose L22 for level change, significantly more than that using L33 $(p<0.001)$, which only accounted for 9.9\%. In contrast with ramp groups, hens preferred to performed Back rather than DM when using ladders, with $62.7 \%$ of level changes were completed by Back for L22 use and $68.5 \%$ for L33 use. Difference between behavioral processes was also shown for ladder use $(p<0.001$, Table 4). However, no association was found between behavioral processes and the ladder type $(p=0.669)$.

Table 4 Proportion of behavioral processes for different ramps and ladders use of the whole adaptation period (from the $2^{\text {nd }}$ day to $14^{\text {th }}$ day)

\begin{tabular}{|c|c|c|c|c|c|c|}
\hline \multirow{2}{*}{\multicolumn{2}{|c|}{$\begin{array}{l}\text { Modification } \\
\text { facilities }\end{array}$}} & \multicolumn{4}{|c|}{$\begin{array}{l}\text { Prevalence of behavioral process } \\
\text { Mean (min, max), \% }\end{array}$} & \multirow{2}{*}{$p$-value } \\
\hline & & DM & Linger & Back & Stay & \\
\hline \multirow{3}{*}{ Ramps } & $\begin{array}{c}30^{\circ} \\
(\mathrm{R} 30)\end{array}$ & $\begin{array}{l}68.4^{\mathrm{A}} \\
(56.8- \\
79.8)\end{array}$ & $\begin{array}{l}3.0^{\mathrm{C}} \\
(0.0- \\
7.8)\end{array}$ & $\begin{array}{c}21.5^{\mathrm{AB}} \\
(14.3- \\
30.8)\end{array}$ & $\begin{array}{l}7.0^{\mathrm{BC}} \\
(0.0- \\
13.6)\end{array}$ & $<0.001$ \\
\hline & $\begin{array}{c}40^{\circ} \\
(\mathrm{R} 40)\end{array}$ & $\begin{array}{l}94.3^{\mathrm{A}} \\
(80.0- \\
100.0)\end{array}$ & $0.0^{\mathrm{B}}$ & $\begin{array}{l}5.7^{\mathrm{B}} \\
(0.0- \\
20.0)\end{array}$ & $0.0^{\mathrm{B}}$ & $<0.001$ \\
\hline & $\begin{array}{l}30^{\circ} \& 50^{\circ} \\
(\mathrm{R} 30 \& 50)\end{array}$ & $\begin{array}{c}60.2^{\text {Aa }} \\
(0.0- \\
100.0)\end{array}$ & $\begin{array}{c}1.0^{\mathrm{BCb}} \\
(0.0- \\
7.1)\end{array}$ & $\begin{array}{c}38.8^{\mathrm{ABa}} \\
(0.0- \\
100.0)\end{array}$ & $0.0^{\mathrm{Cb}}$ & $<0.001$ \\
\hline \multirow{2}{*}{ Ladders } & $\begin{array}{l}\text { 22-cm step } \\
\text { (L22) }\end{array}$ & $\begin{array}{c}11.3^{\mathrm{BC}} \\
(0.0- \\
27.3)\end{array}$ & $\begin{array}{l}0.6^{\mathrm{C}} \\
(0.0- \\
4.3)\end{array}$ & $\begin{array}{l}62.7^{\mathrm{A}} \\
(34.6- \\
87.0)\end{array}$ & $\begin{array}{c}25.4^{\mathrm{AB}} \\
(4.3- \\
46.2)\end{array}$ & $<0.001$ \\
\hline & $\begin{array}{l}\text { 33-cm step } \\
\text { (L33) }\end{array}$ & $\begin{array}{c}4.4^{\mathrm{Bbc}} \\
(0.0- \\
25.0)\end{array}$ & $0.0^{\mathrm{Bc}}$ & $\begin{array}{c}68.5^{\mathrm{Aa}} \\
\left(0.0^{-}\right. \\
100.0)\end{array}$ & $\begin{array}{c}27.1 \text { ABab } \\
(0.0- \\
100.0)\end{array}$ & $<0.001$ \\
\hline
\end{tabular}

Note: ${ }^{\text {a-b: }}$ Different superscript lowercases within a row indicate difference at level of $p<0.05$; ${ }^{\text {A-B: }}$ Different superscript capital letters within a row indicate difference at level of $p<0.01$. DM, Linger, Back and Stay are behavioral processes during modification facilities use and according definitions can be found in Table 1.

No significant modification $\times$ days of adaptation interaction effect on behaviors was found. Specifically, percentage of hens engaging in feeding in ramp compartments was 6.5 (95\%CI was 2.6-10.3) more than that in ladder compartments ( $p=0.002)$. Also, there were $2.1 \%$ more hens exploring (95\%CI was $0.4 \%-3.7 \%$, $p=0.015$ ) but $5.1 \%$ fewer hens standing (95\%CI was $0.8 \%-9.5 \%$, $p=0.021$ ) in ramp compartments. Days of adaptation significantly affected the proportion of hens displaying feeding, lying, comfort behaviors and exploring. With adaptation time increasing, more hens were observed feeding $(p<0.001)$ and proportion of hens lying was getting less $(p<0.001)$. Remarkable change of proportion of hens displaying comfort behaviors was observed $(p=0.003)$ but no regular rule could be found. For exploring hens, an increase of percentage was shown from the $4^{\text {th }}$ day but only on the $13^{\text {th }}$ day a significant difference was found compared with the $2^{\text {nd }}$ and the $3^{\text {rd }}$ day (both $p=0.041$ ). Detailed information was presented in Figure 6 .
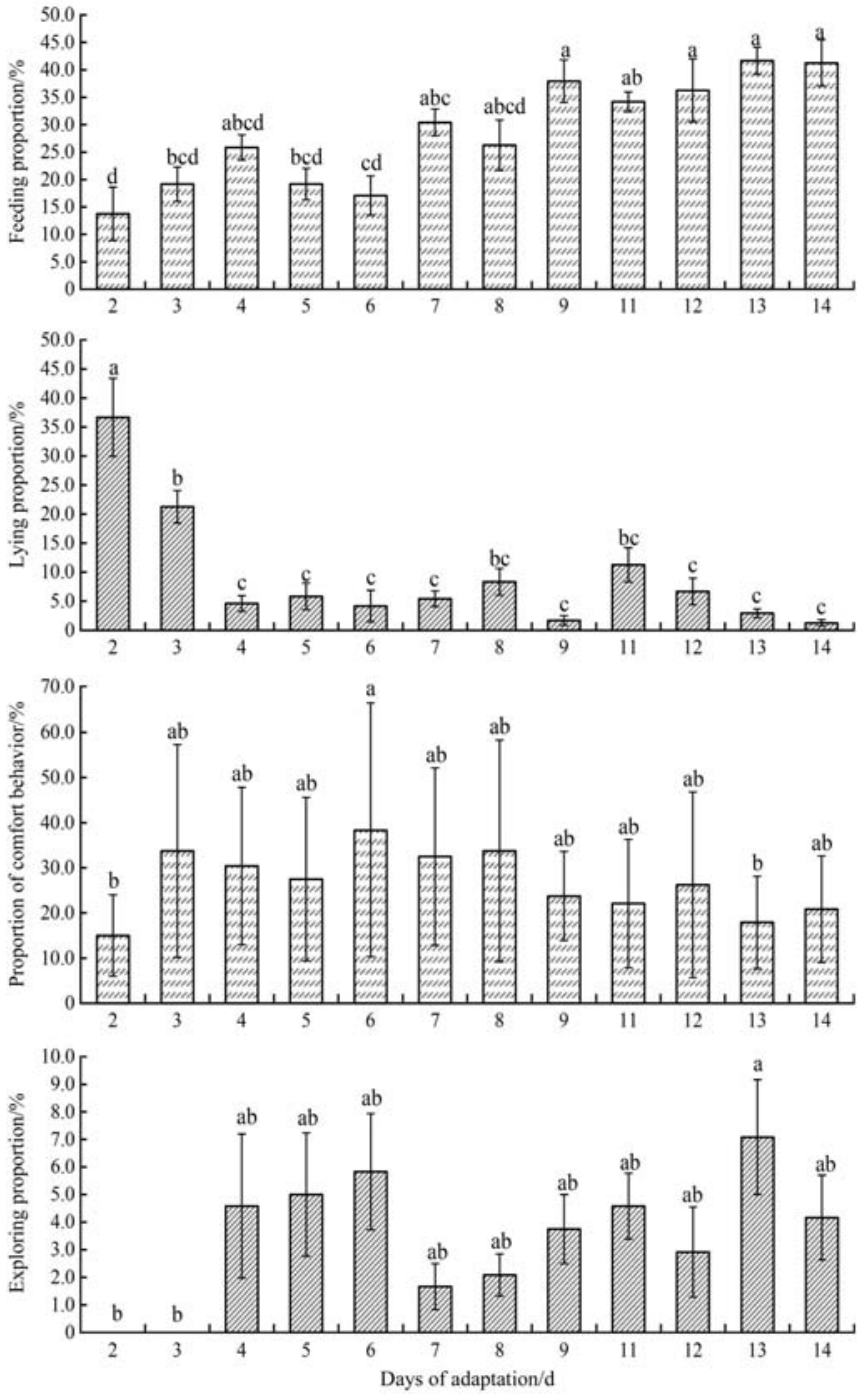

Note: Letters a-d within a row indicate difference at level of $p<0.05$.

Figure 6 Proportion of hens performing feeding, lying, comfort behavior and exploring during observed over time after transfer

\subsection{Modification on distribution of eggs}

The laying rate had no significant difference between ramp group and ladder group ( $p>0.05$ ), which had reached $50 \%$ at the age of 22 weeks and both gotten to the production peak that was over $90 \%$ at 24 weeks of age simultaneously. For nest eggs, the proportion in ramp group was significantly higher than that in ladder group from the age of 22 weeks to 25 weeks ( $p<0.01$ for all, Figure 7). On the contrary, the proportion of system eggs and floor eggs in ladder group was found higher than that in ramp group, as shown in Figure 7.

\section{Discussion}

\subsection{Modifications of perchery system on early adaptation of} birds

In ramp compartments, proportion of hens on tiered platforms was significantly more than that in ladder compartments during the whole observation period. By the end of observation period, the averaged percentage of hens on tiered platforms in ramp group increased to $76.7 \%$ in the daytime and this proportion got to $95.0 \%$ at night. By contrast, in ladder group, the majority of birds stayed on system floor instead, $85.0 \%$ for daytime and $89.6 \%$ for the night on the $14^{\text {th }}$ day, which was nearly or more than four times the percentages compared with ramp group. Comparison of birds' distribution between daytime and night-time in ramp group showed 

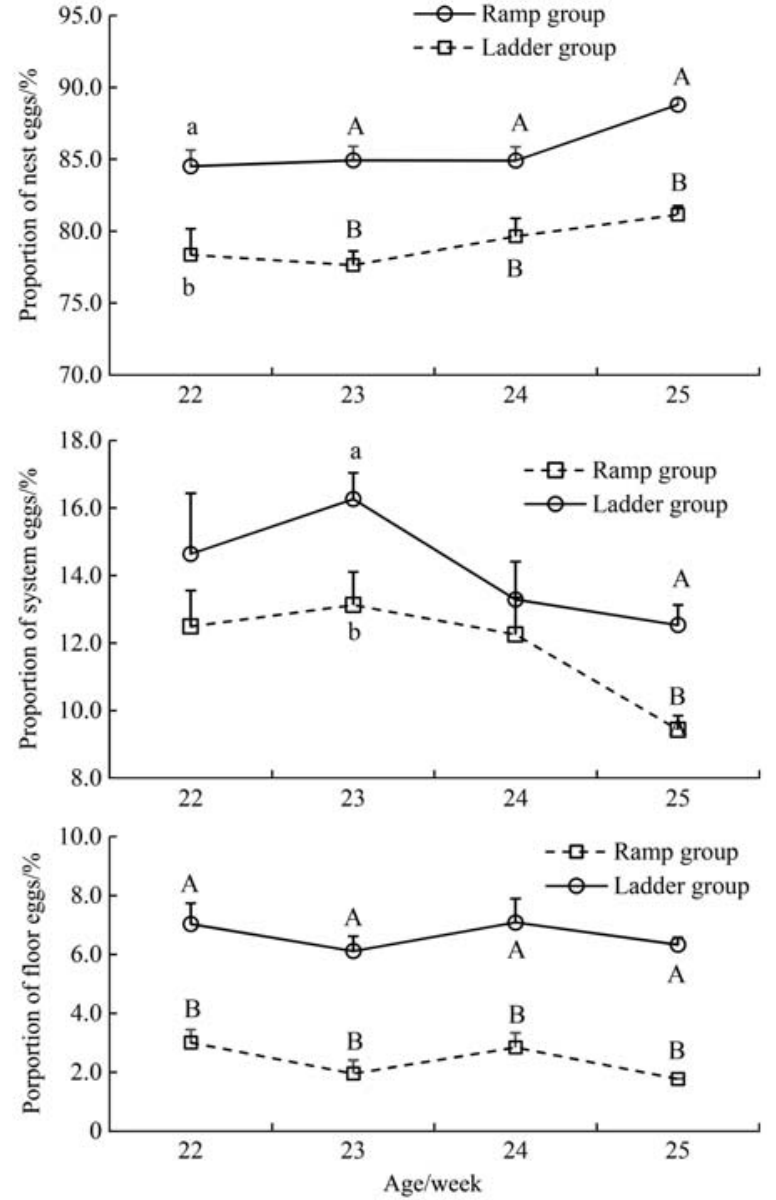

Note: Letters a-b indicate difference within age at the level $p<0.05$ and letters A-B indicate difference within age at the level $p<0.01$.

Figure 7 Proportion of nest eggs, system egg and floor eggs with age

that there was an increase of percentage of birds above the floor, in accord with the results in several earlier researches ${ }^{[3,27,28]}$. Birds' move towards to the upper space is thought as an important part of the anti-predator behavior ${ }^{[29,30]}$ and such night-time roosting is a natural motivation of birds concerning welfare ${ }^{[31]}$. However, an increase of the proportion of hens on system floor in ladder group is unexpected. It could be interpreted as a reaction of refuge seeking from dangers at night by rejoining the group.

Although proportion of hens above the system floor increased over time in both modification groups, not all change condition was identical for platforms of different tier. It could be noticed that proportion of hens on the $1^{\text {st }}$ platform decreased over time but increased on the $3^{\text {rd }}$ platform at the same time for both day and night. These results showed that modification of ramps ensures birds better adaptation in multi-tier perchery system as indicated by the continuous increasing and higher proportion of hens getting onto tiered platforms in ramp group than ladder group. This study confirms the recent finding that inclusion of ramps is advantageous for increasing the ease of access to important resources ${ }^{[23]}$, as shown in present study birds in ramp group could easily get onto tiered platforms for feed and water, even for the nest tier which would be discussed later. It is mainly because that inclusion of ramps at specific location can facilitate the procedure to negotiate a level change primarily by providing a continuous path ${ }^{[21]}$. By contrast, birds in ladder group in present study needed to accomplish two or three consecutive jumps to get onto the $1^{\text {st }}$ platform from the system floor, which requires a series of behaviors like orientation, crouch and jump in quick succession, and landing. As reported, ground-dwelling birds preferred wing-assisted incline running (WAIR) or walking, rather than flying, to reach elevated refuges ${ }^{[32,33]}$, possibly because less aerodynamic output is required for both WAIR and walking than flying ${ }^{[34]}$. However, it was unexpected that very few birds got access to the tiered platforms in ladder group and we attributed this result to birds' weakness of spatial cognition. Because it was reported that birds were capable to get the food presented on the tier of $40 \mathrm{~cm}$ above the floor even they were provided with perches late in 8 weeks of age ${ }^{[35]}$. In present study, all birds did not have perch access before 9 weeks of age, which was thought unfriendly for the development of spatial cognition ability ${ }^{[35,36]}$. Besides, furnishing perches in rearing cages were installed only $12 \mathrm{~cm}$ above the cage floor, which was much lower than a ladder step in present study. So it might be difficult for birds to negotiate the transition steps of $22 \mathrm{~cm}$ or $33 \mathrm{~cm}$ in ladder group. Behavioral observation found that birds used furnishing perches primarily by stepping on it, resulting in a lack of flight exercise which is needed for ladder use in perchery system.

In later $6 \mathrm{~d}$ of observation period, even though not obviously, an increasing percentage of birds above the floor compared with that of the beginning $6 \mathrm{~d}$ indicated that birds are willing to use the three-dimensional space. As reported by Tanaka and Hurnik ${ }^{[37]}$, only an average of $22 \%$ of birds utilized the central areas above the system floor in the first 2 weeks after housing even though all birds were reared in floor pens furnished with roosts before. They pointed out that birds might take 2 weeks or more to stabilize in tiered-floor positions of the aviary ${ }^{[38]}$. So birds in present ladder group might take more time to get familiar with the multi-tiered perchery system based on their pre-rearing condition.

\subsection{Utilization of ramp and ladder and behavioral difference}

Results showed that ramps were used more frequently than ladders which can be interpreted to be related with birds' spatial ability and preference of behaviors when using facilities, as explained above that birds in ramp group had easier path for level change. Preference for R30 to both R40 and R30\&50 was shown. This study attribute the variant use of ramps to the angle effects, as refereed by LeBlanc et al. ${ }^{[25]}$ that inclines affect birds' behavior. They found that no more than $40^{\circ}$ were easily negotiated by both chicks and adult fowls without wing assist and more WAIR behaviors were performed with incline angle increasing. Behavioral change with ramp angle was also found by Dial and Jackson $^{[39]}$. That might partially explain why hens also performed Linger, Back, and Stay rather than performing DM only when using R30, and the highest ratio of Back process was found when using R30\&50. Besides, it is thought that a steeper incline is more difficult to walk up and keep balanced on it, as a few upward aborted attempts by birds were found when using $45^{\circ} \operatorname{ramp}^{[24]}$. Thus Linger and Stay were merely occurred when using R40 and R30\&50.

For ladder use, no association was found between birds' behavioral processes and ladder type and birds preferred to perform Back rather than DM. Those results further confirmed that it was the weakness of birds' spatial cognition resulting in the lower ratio of success for level change. Because birds were being reared in cages with perch access later than 8 weeks of age and the insufficient development of perching behavior, which is thought related with spatial ability in complex environment ${ }^{[19]}$.

More hens engaged in feeding and exploring (feeding: $p=0.002$; 
exploring: $p=0.015)$, and fewer hens engaged in standing ( $p=0.021)$ in ramp group compared with those in ladder group. With an easy access for upper tiers, there should be higher probability for hens in ramp group to eat simultaneously based on the sufficient feeding space applied. Inversely, hens in ladder compartments had rather crowded or insufficient space to eat so that not all starving birds could immediately get feed and had to eat in batches. In both groups, an increasing proportion of hens were observed feeding $(p<0.001)$ and a decreasing proportion of hens lying $(p<0.001)$ over time after transfer. It accords with the finding by Shinmura et al. ${ }^{[40]}$, which showed that the proportion of feeding birds increased with time in the initial 2 weeks. However, the proportion of birds feeding in present study at the end of adaptation period was over $40 \%$, much higher than the data obtained by Shinmura et al. ${ }^{[0]}$, which was nearly $23 \%$ at most. The main reason might be that feed trough was available for birds even on the system floor. Besides, a higher proportion of birds of ramp group in present study got onto tiered platforms where they could get feed easily. When more space and resources available, the crowding condition were alleviated and less lying was shown over time.

\subsection{Effects of modification on distribution of eggs}

A higher proportion of nest eggs and a much lower ratio of system eggs and floor eggs were found in ramp group from the age of 22 weeks to 25 weeks (for all indicators $p<0.01$ at each week, Figure 7). Egg distribution was thought highly related with the early distribution of birds, which impacted the effective utilization of space and resources by birds. As reported by Colson et al. ${ }^{[14]}$, floor-reared hens laid more eggs on the floor than aviary-reared hens, with which the poor capacity for long jumps was thought strongly associated. Cage-reared hens in present study had poor spatial ability, which was obviously reflected in ladder group, where the majority of hens stayed on the floor during the first 2 weeks. Although distribution of birds in later period after adaptation was not recorded, latent or poor adaptation of birds in ladder group was inevitable. Behavioral observation found that related exploratory behaviors like nest visits or inspection by hens were much earlier in ramp group. Several researches also demonstrated that percentage of floor eggs in aviary systems alike was higher than that in free-range and floor systems ${ }^{[3,41]}$, mainly depended on birds' adaptation in such multi-tier systems.

\section{Conclusions}

Modification of ramps is more suitable for birds' early adaptation and is beneficial to decrease floor eggs in perchery system of multi-tier, especially for pullets reared in conventional cages. Results showed that birds preferred ramps to achieve level change, among which ramp of $30^{\circ}$ was of the mostly frequent use with various behavioral processes performed, indicating that an easy path for level change is crucial for birds to effectively use the aerial space and resources. This study recommend to provide ramps for birds in multi-tier systems in the early adaptation period and the angle of ramps would better be no more than $40^{\circ}$.

\section{Acknowledgements}

Many thanks to the staff of the rearing farm of Beijing Huadu Yukou Poultry Co. Ltd. for their cooperation on pullets selection before transfer, and also to the staff of experiment farm for their attentive animal care after housing. This study was funded by China Agricultural Research System-National Technology System for Layer Industry (CARS-40-19K) and National Natural Science Foundation of China (31601981).

\section{[References]}

[1] Appleby M C, Smith S F, Hughes B O. Nesting, dust bathing and perching by laying hens in cages: effects of design on behaviour and welfare. Br Poult Sci, 1993; 34(5): 835-847.

[2] Baxter M R. The welfare problems of laying hens in battery cages. Vet Rec, 1994; 134: 614-619.

[3] Abrahamsson P, Tauson R. Aviary systems and conventional cages for laying hens: Effects on production, egg quality, health and bird location in three hybrids. Acta Agriculturae Scandinavica A-Animal Sciences, 1995; 45(3): 191-203.

[4] Tauson R. Furnished cages and aviaries: Production and health. World's Poult Sci J, 2002; 58(1): 49-63.

[5] Appleby M C. The European Union ban on conventional cages for laying hens: History and prospects. J Appl Anim Welf Sci, 2003; 6(2): 103-121.

[6] Directive E U. Council directive 1999/74/EC of 19 July 1999 laying down minimum standards for the protection of laying hens. Official Journal of the European Communities, 1999; L203: 53-57.

[7] Greene J, Cowan T. Table egg production and hen welfare: the UEP-HSUS agreement and HR 3798. Available: http://www.fas.org/sgp/ crs/misc/R42534.pdf.

[8] Campbell D L, Goodwin S L, Makagon M M, Swanson J C, Siegford J M. Failed landings after laying hen flight in a commercial aviary over two flock cycles. Poult Sci, 2016; 95(1): 188-197.

[9] Steenfeldt S, Nielsen B L. Welfare of organic laying hens kept at different indoor stocking densities in a multi-tier aviary system. I: egg laying, and use of veranda and outdoor area. Animal, 2015; 9(9): 1509-1517.

[10] Shields S, Duncan I J H. An HSUS Report: a comparison of the welfare of hens in battery cages and alternative systems. Available: https://animalstudiesrep-ository.org/hsus_reps_impacts_on_animals/18.

[11] Leyendecker M, Hamann H, Hartung J, Kamphues J, Neumann U, Surie C, et al. Keeping laying hens in furnished cages and an aviary housing system enhances their bone stability. Br Poult Sci, 2005; 46(5): 536-544.

[12] Wilkins L J, McKinstry J L, Avery N C, Knowles T G, Brown S N, Tarlton $\mathrm{J}$, et al. Influence of housing system and design on bone strength and keel bone fractures in laying hens. Vet Rec, 2011; 169(16): 414-414.

[13] Colson S, Arnould C, Huonnic D, Michel V. Influence of two rearing systems for pullets, rearing aviaries and furnished floor, on space use and production in laying aviaries. Anim Sci Pap Rep, 2005; 23(S1): 85-93.

[14] Colson S, Arnould C, Michel V. Influence of rearing conditions of pullets on space use and performance of hens placed in aviaries at the beginning of the laying period. Appl Anim Behav Sci, 2008; 111(3-4): 286-300.

[15] Brantsæter M, Nordgreen J, Rodenburg T B, Tahamtani F M, Popova A, Janczak A M. Exposure to increased environmental complexity during rearing reduces fearfulness and increases use of three-dimensional space in laying hens (Gallus gallus domesticus). Front Vet Sci, 2016; 3: 14.

[16] Casey-Trott T M, Guerin M T, Sandilands V, Torrey S, Widowski T M. Rearing system affects prevalence of keel-bone damage in laying hens: A longitudinal study of four consecutive flocks. Poult Sci, 2017; 96(7): 2029-2039.

[17] Janczak A M, Riber A B. Review of rearing-related factors affecting the welfare of laying hens. Poult Sci, 2015; 94(7): 1454-1469.

[18] Tahamtani F M, Nordgreen J, Nordquist R E, Janczak A M. Early life in a barren environment adversely affects spatial cognition in laying hens (Gallus gallus domesticus). Front Vet Sci, 2015; 2: 3.

[19] Wichman A, Heikkilä M, Valros A, Forkman B, Keeling L J. Perching behaviour in chickens and its relation to spatial ability. Appl Anim Behav Sci, 2007; 105(1-3): 165-179.

[20] Gunnarsson S, Keeling L J, Svedberg J. Effect of rearing factors on the prevalence of floor eggs, cloacal cannibalism and feather pecking in commercial flocks of loose housed laying hens. Br Poult Sci, 1999; 40(1): 12-18.

[21] Stratmann A, Fröhlich E K F, Gebhardt-Henrich S G, Harlander-Matauschek A, Würbel H, Toscano M J. Modification of aviary design reduces incidence of falls, collisions and keel bone damage in laying hens. Appl Anim Behav Sci, 2015; 165: 112-123.

[22] Heerkens J L T, Delezie E, Ampe B, Rodenburg T B, Tuyttens F A M. Ramps and hybrid effects on keel bone and foot pad disorders in modified aviaries for laying hens. Poult Sci, 2016; 95(11): 2479-2488.

[23] Pettersson I C, Weeks C A, Nicol C J. The effect of ramp provision on the accessibility of the litter in single and multi-tier laying hen housing. Appl Anim Behav Sci, 2017; 186: 35-40.

[24] Pettersson I C, Weeks C A, Norman K I, Nicol C J. The ability of laying 
pullets to negotiate two ramp designs as measured by bird preference and behaviour. PeerJ, 2017; 5: e4069.

[25] LeBlanc C, Tobalske B, Bowley S, Harlandermatauschek A. Development of locomotion over inclined surfaces in laying hens. Animal, 2018; 12(3): 585-596.

[26] Zheng H Y, Yang L, Li B M, Zhou B G. Effect of perch provision in rearing cages on pullets' adaptability to perch system before and after transfer. Transactions of the CSAE, 2018; 34(13): 225-232. (in Chinese)

[27] Carmichael N L, Walker W, Hughes B O. Laying hens in large flocks in a perchery system: Influence of stocking density on location, use of resources and behaviour. Br Poult Sci, 1999; 40(2): 165-176.

[28] Odén K, Keeling L J, Algers B. Behaviour of laying hens in two types of aviary systems on 25 commercial farms in Sweden. Br Poult Sci, 2002; 43(2): 169-181.

[29] Appleby M C, Mench J A, Hughes B O. Poultry behaviour and welfare. Wallingford, U.K., CABI Publishing, 2004.

[30] Schrader L, Müller B. Night-time roosting in the domestic fowl: The height matters. Appl Anim Behav Sci, 2009; 121(3-4): 179-183.

[31] Olsson I A, Keeling L J. Night-time roosting in laying hens and the effect of thwarting access to perches. Appl Anim Behav Sci, 2000; 68(3): 243-256.

[32] Dial K P. Wing-assisted incline running and the evolution of flight. Science, 2003; 299(5605): 402-404.

[33] Dial K P, Jackson B E, Segre P. A fundamental avian wing-stroke provides a new perspective on the evolution of flight. Nature, 2008; 451(7181): 985-989.

[34] Tobalske B W, Dial K P. Aerodynamics of wing-assisted incline running in birds. J Exp Biol, 2007; 210(10): 1742-1751.

[35] Gunnarsson S, Yngvesson J, Keeling L J, Forkman B. Rearing without early access to perches impairs the spatial skills of laying hens. Appl Anim Behav Sci, 2000; 67(3): 217-228.

[36] Kozak M, Tobalske B, Martins C, Bowley S, Wuerbel H, Harlander-Matauschek A. Use of space by domestic chicks housed in complex aviaries. Appl Anim Behav Sci, 2016: 181: 115-121.

[37] Tanaka T, Hurnik J F. Research Note: The behaviour of young layers during two weeks in aviary and cages. Poult Sci, 1991; 70(2): 404-407.

[38] Tanaka T, Hurnlk J F. Comparison of behaviour and performance of laying hens housed in battery cages and an aviary. Poult Sci, 1992; 71(2): 235-243.

[39] Dial K P, Jackson B E. When hatchlings outperform adults: locomotor development in Australian brush turkeys (Alectura lathami, Galliformes). Proc R Soc B, 2010; 278(1712): 1984.

[40] Shinmura T, Eguchi Y, Lietake K, Tanaka T. Behavioral changes in laying hens after introduction to battery cages, furnished cages and an aviary. Anim Sci J, 2006; 77(2): 242-249.

[41] Petek M. The productivity of commercial laying hens housed in battery cage, aviary, perchery and free-range housing systems. In Proceeding of the 22th Worlds Poultry Congress. Istanbul, Turkey, 2004; pp.8-13. 